RIGO, Mônica Giusti. Meio ambiente igualitário: análise da relação entre a justiça equitativa de Rawls e o princípio da "não-regressão" de Michel Prieur. Revista Eletrônica Direito e Política, Programa de Pós-Graduação Stricto Sensu em Ciência Jurídica da UNIVALI, Itajaí, v.10, n.1, edição especial de 2015. Disponível em: www.univali.br/direitoepolitica - ISSN 1980-7791.

\title{
MEIO AMBIENTE IGUALITÁRIO: ANÁLISE DA RELAÇÃO ENTRE A JUSTIÇA EQUITATIVA DE RAWLS E O PRINCÍPIO DA "NÃO- REGRESSÃO" DE MICHEL PRIEUR
}

\author{
EQUAL ENVIRONMENT: ANALYSIS OF THE RELATIONSHIP BETWEEN THE \\ RAWLS COURT OF EQUITABLE AND THE MICHEL PRIEUR'S PRINCIPLE \\ "NON-REGRESSION"
}

Mônica Giusti Rigo ${ }^{1}$

SUMÁRIO: Introdução; 1 . Dois princípios da Justiça; 2 . O princípio da igualdade equitativa de oportunidades; 3 . O princípio da diferença; 4 . Relação entre os princípios de Rawls e o princípio da não regressão. Considerações Finais; Referências.

RESUMO: Este artigo tem como mote central fazer uma relação entre a teoria de justiça de John Rawls e sua possível relação com o princípio da "não-regressão" de Michel Prieur. Neste sentido, faz-se um breve apanhado sobre os princípios gerais desta teoria de justiça igualitária. Busca-se demonstrar como John Rawls preceitua a distribuição dos bens sociais de modo a formar uma justiça igualitária em meios e recursos. Objetiva-se um apanhado geral dos princípios da diferença e da igualdade equitativa de oportunidades. Ao final, quando a teoria de Rawls se encontra esmiuçada relação deste e o princípio da não regressão.

Palavras-chave: Justiça; Equidade; Bens; Recursos.

ABSTRACT: This article has as its central theme to make a relationship between the theory of justice of John Rawls and its relation to the principle of "nonregression" Michel Prieur. In this sense, it is a brief overview on the general principles of equal justice theory. It is quite evident as John Rawls stipulates the distribution of social goods to form an egalitarian justice means and resources. The purpose is an overview of the principles of difference and fair equality of

\footnotetext{
${ }^{1}$ Mestranda do programa de Pós-Graduação do Curso de Direito da Universidade de Passo Fundo UPF, bolsista do PROSUP/CAPES. E-mail: Monica.grigo@hotmail.com
} 
RIGO, Mônica Giusti. Meio ambiente igualitário: análise da relação entre a justiça equitativa de Rawls e o princípio da "não-regressão" de Michel Prieur. Revista Eletrônica Direito e Política, Programa de Pós-Graduação Stricto Sensu em Ciência Jurídica da UNIVALI, Itajaí, v.10, n.1, edição especial de 2015. Disponível em: www.univali.br/direitoepolitica - ISSN 1980-7791.

opportunity. At the end, when Rawls's theory is teased this relationship and the principle of non-regression.

Keywords: Justice; Equitable; Belongings; Resources.

\section{INTRODUÇÃO}

O presente artigo traz um apanhado geral da teoria de John Rawls, tendo como centro traçar os principais objetivos e estratégias da teoria da justiça equitativa em John Rawls. John Rawls tem em sua obra uma nova teoria da justiça, tendo como base dois princípios da justiça norteadores do sistema de distribuição de bens e riquezas da sociedade. "A argumentação de Rawls é construída com base em determinados conceitos, que tornam a obra consistente e bem arquitetada. Essa elaboração contempla, sobretudo, os conceitos de posição original, os princípios da justiça e o consenso sobreposto"².

Essa teoria da justiça igualitária busca uma distribuição dos recursos da sociedade dentre todos que fazem parte desta, em especial aos menos favorecidos que não devem restar em desvantagens devido aos fatores naturais pessoais. Deste modo, busca-se verificar de que modo o meio ambiente sadio pode ser enquadrado como um recurso a ser distribuído dentro da teoria de Rawls.

Parte-se, para tanto, da demonstração de como a cooperação social tem influência na justiça equitativa, bem como, de que modo Rawls trouxe essa nova teoria da justiça como uma alternativa às teorias existentes.

Neste sentido, "o filósofo americano define instituição como sendo um sistema público de regras que determina funções e posições fixando, por exemplo, os respectivos direitos e deveres, bem como poderes e imunidades" ${ }^{3}$. Além disso,

\footnotetext{
2 ZAMBAM, Neuro José. A teoria da justiça em John Rawls: uma leitura. Passo Fundo: Ed. Universidade de Passo Fundo, 2004. p. 47.

${ }^{3}$ FARIAS, José Fernando de Castro. Ética, justiça e direito. Rio de Janeiro: Lumen Juris, 2004. p. 40.
} 
RIGO, Mônica Giusti. Meio ambiente igualitário: análise da relação entre a justiça equitativa de Rawls e o princípio da "não-regressão" de Michel Prieur. Revista Eletrônica Direito e Política, Programa de Pós-Graduação Stricto Sensu em Ciência Jurídica da UNIVALI, Itajaí, v.10, n.1, edição especial de 2015. Disponível em: www.univali.br/direitoepolitica - ISSN 1980-7791.

de acordo com esses dois princípios trazidos por Rawls certas ações seriam justas ou injustas no sistema.

\section{DOIS PRINCÍPIOS DA JUSTIÇA}

Primeiramente, deve-se trazer que Rawls opta por dois princípios da justiça que deverão nortear o sistema do direito à aplicação nas instituições básicas da sociedade. Parte, assim, de um sistema de compreensão de justiça pública, onde todos acolhem os princípios norteadores da justiça ${ }^{4}$.

Neste sistema todos os indivíduos que compõe a sociedade acolhem estes princípios e sabem que todos dentro da sociedade os acolhem também. "A justiça é a primeira virtude das instituições sociais" ${ }^{\prime 5}$. Ainda, ressalta o autor:

(...) a idéia norteadora é que os princípios da justiça para a estrutura básica da sociedade são o objeto do consenso original. São esses princípios que pessoas livres e racionais, preocupadas em promover seus próprios interesses, aceitariam numa posição inicial de igualdade como definidores dos termos fundamentais de sua associação. Esses princípios devem regular todos os acordos subseqüentes; especificam os tipos de cooperação social que se podem assumir e as formas de governo que se podem estabelecer. A essa maneira de considerar os princípios da justiça eu chamarei de justiça como equidade ${ }^{6}$.

As instituições básicas da sociedade, ou "estrutura básica da sociedade", consistem como objeto principal da sociedade, regrando a maneira como é feita a distribuição das vantagens, direitos e deveres fundamentais. Para Rawls "não existe um critério independente que possa nos dizer o que é justo fazer, embora existam procedimentos que podem ajudar-nos a chegar a resultados equitativos" $"$.

\footnotetext{
${ }^{4}$ RAWLS, John. Uma teoria da justiça. São Paulo: Martins Fontes, 2000. p. 5.

${ }^{5}$ RAWLS, John. Uma teoria da justiça. São Paulo: Martins Fontes, 2000. p. 3.

${ }^{6}$ RAWLS, John. Uma teoria da justiça. São Paulo: Martins Fontes, 2000. p. 12.

7 GARGARELA. As teorias da justiça depois de Rawls. Um breve manual de filosofia política. p. 20.
} 
RIGO, Mônica Giusti. Meio ambiente igualitário: análise da relação entre a justiça equitativa de Rawls e o princípio da "não-regressão" de Michel Prieur. Revista Eletrônica Direito e Política, Programa de Pós-Graduação Stricto Sensu em Ciência Jurídica da UNIVALI, Itajaí, v.10, n.1, edição especial de 2015. Disponível em: www.univali.br/direitoepolitica - ISSN 1980-7791.

Os princípios básicos desta teoria são escolhidos por pessoas desprovidas de informações das contingências da própria vida, tendo alto grau de imparcialidade de escolhas. Estes princípios estão destinados a aplicação na estrutura básica da sociedade.

Os sujeitos que Rawls imagina surgem afetados por uma circunstância particular. Ocorre que estão sob um "véu de ignorância", que os impede de conhecer qual é sua classe ou seu status social, a sorte ou desventura que tiveram na distribuição de capacidades naturais, sua inteligência, sua força, sua raça, a geração à qual pertencem etc. Tampouco conhecem suas concepções do bem ou suas propensões psicológicas específicas. Por outro lado, esse "véu" não os impede de reconhecer certas proposições gerais, tais como as descobertas básicas que as ciências sociais fizeram em matéria de economia, psicologia social etc ${ }^{8}$.

O chamado "véu da ignorância" seria a "posição original" para a escolha dos princípios norteadores do sistema de justiça. "O desinteresse mútuo apresentase como uma maneira sutil de antepor o recuso da razão prática à escolha dos princípios, modelando restrições para que possamos adotar uma concepção política de justiça adequada à uma sociedade democrática constitucional ${ }^{\prime 9}$.

Porém, para que este sistema de escolhas de princípios seja efetivamente aplicável depende diretamente da estabilidade do modo de cooperação social na sociedade a qual estiver inserido. Assim, "uma sociedade bem organizada é aquela direcionada para promover o bem de seus membros"10.

Deste modo, segundo a teoria do "véu da ignorância", os princípios escolhidos não estarão subordinados as escolhas particulares e egoístas, mas pensando na distribuição dos recursos à sociedade como um todo. Pois os sujeitos representantes que farão a sua escolha estarão desprovidos de conhecimento a

\footnotetext{
${ }^{8}$ GARGARELA, Roberto. As teorias da justiça depois de Rawls. Um breve manual de filosofia política. São Paulo: Martins Fontes, 2008. p. 21.

${ }^{9}$ MÖLLER, Josué Emilio. A justiça como eqüidade em John Rawls. Porto Alegre: S. A. Frabris, 2006. p. 49.
}

${ }^{10}$ GARGARELA. As teorias da justiça depois de Rawls. Um breve manual de filosofia política. p. 19. 
RIGO, Mônica Giusti. Meio ambiente igualitário: análise da relação entre a justiça equitativa de Rawls e o princípio da "não-regressão" de Michel Prieur. Revista Eletrônica Direito e Política, Programa de Pós-Graduação Stricto Sensu em Ciência Jurídica da UNIVALI, Itajaí, v.10, n.1, edição especial de 2015. Disponível em: www.univali.br/direitoepolitica - ISSN 1980-7791.

respeito da classe social e modo de vida que leva. Assim, o representante resta obrigado a decidir de acordo com o justo a todas as classes sociais existentes.

É preciso ter em vista que a concepção política da justiça, corporificada nos princípios selecionados por cidadãos ideais, deverá defluir naturalmente das instituições que farão parte do aparato estatal. Por esta razão, os termos diretivos não podem sofrer quaisquer influências particulares de futuros membros da sociedade organizada, sob pena de insucesso do acordo em decorrência de não traduzir termos cooperativos próprios para uma sociedade justa. Em outras palavras, podemos dizer que a justiça de um sistema cooperativo dependerá, desde o início, do modo pelo qual ele se constitui ou se estrutura ${ }^{11}$.

Assim sendo, a importância do véu da ignorância proposta por Rawls se impõe, pois os representantes da sociedade que irão escolher os princípios a serem seguidos não tem conhecimento de sua posição na sociedade.

Deste modo, faz as escolhas pelo bem comum, de acordo com o que beneficia o bem estar de todos na sociedade, deste modo ninguém seria "favorecido ou desfavorecido pela sorte natural ou por circunstâncias sociais em decorrência da escolha dos princípios"12.

Sendo assim, ao selecionarem os princípios norteadores da justiça os participantes pensariam na sociedade como um todo, pois, naquele momento, estariam desprovidos de informações a respeito da própria vida.

Adotando-se a chamada "regra maximim", na qual "deverá ser adotada a alternativa cujo pior resultado for superior ao pior resultado das outras alternativas"13. Assim, diante do desconhecimento de sua própria situação, as escolhas seriam imparciais, considerando nesta alternativa todos os participantes da sociedade como beneficiados.

Os princípios formulados por Rawls podem ser sintetizados como a garantia do acesso às liberdades iguais para todos. A

\footnotetext{
${ }^{11}$ MÖLLER. A justiça como eqüidade em John Rawls. p. 47.

12 RAWLS, John. Uma teoria da justiça. São Paulo: Martins Fontes, 2000. p. 20.

13 GARGARELA. As teorias da justiça depois de Rawls. Um breve manual de filosofia política. p. 23-24.
} 
RIGO, Mônica Giusti. Meio ambiente igualitário: análise da relação entre a justiça equitativa de Rawls e o princípio da "não-regressão" de Michel Prieur. Revista Eletrônica Direito e Política, Programa de Pós-Graduação Stricto Sensu em Ciência Jurídica da UNIVALI, Itajaí, v.10, n.1, edição especial de 2015. Disponível em: www.univali.br/direitoepolitica - ISSN 1980-7791.

igualdade de oportunidades $e$ as diferenças, quando existirem, devem reverter em benefício dos menos favorecidos da sociedade. Este último é chamado "princípio da diferença" ${ }^{14}$.

Os participantes teriam por motivação na escolha dos princípios os bens primários, que podem ser definidos como aqueles considerados indispensáveis a vida, não importando o tipo de vida de cada cidadão, mas bens que todos necessitem para a sobrevivência. Como objeto das expectativas se tem os bens sociais primários, estes "são direitos, liberdades e oportunidades, assim como renda e riqueza"15.

Os bens primários podem ser de dois tipos, naturais e sociais. Os bens primários sociais são aqueles "diretamente distribuídos pelas instituições sociais (como a riqueza, as oportunidades, os direitos); e os bens primários de tipo natural, que não são distribuídos diretamente pelas instituições sociais (como, por exemplo, os talentos, a saúde, a inteligência etc. $)^{\prime 16}$.

Este momento de escolha dos princípios é denominado como posição original, sendo está "artifício de representação deslocado da sociedade, a partir do qual, um acordo equitativo válido para todos possa ser estabelecido, sabendo-se das diferentes concepções morais, religiosas e políticas que compõem uma sociedade pluralista $^{17 \prime \prime}$.

O primeiro princípio no qual "cada pessoa deve ter um direito igual ao mais amplo sistema total de liberdades básicas iguais que seja compatível com um sistema semelhante de liberdade para todos"18. Este princípio é denominado por alguns autores como o "princípio da igualdade de tratamento ou princípio das

\footnotetext{
14 ZAMBAM. A teoria da justiça em John Rawls: uma leitura. p. 48.

15 RAWLS, John. Uma teoria da justiça. São Paulo: Martins Fontes, 2000. p. 98.

${ }^{16}$ GARGARELA. As teorias da justiça depois de Rawls. Um breve manual de filosofia política. p. 23.

17 ZAMBAM. A teoria da justiça em John Rawls: uma leitura. p. 51.

18 KUKATHAS, Chandran; PETTIT, Philip. Rawls: uma teoria da justiça e seus críticos. Lisboa: Gadiva, 1995. p. 59.
} 
RIGO, Mônica Giusti. Meio ambiente igualitário: análise da relação entre a justiça equitativa de Rawls e o princípio da "não-regressão" de Michel Prieur. Revista Eletrônica Direito e Política, Programa de Pós-Graduação Stricto Sensu em Ciência Jurídica da UNIVALI, Itajaí, v.10, n.1, edição especial de 2015. Disponível em: www.univali.br/direitoepolitica - ISSN 1980-7791.

liberdades iguais" ${ }^{19}$, que determina que todas as pessoas tem o direito a liberdades individuais básicas assegurado.

Este princípio determina a igualdade entre todos dentro do Estado, preservando as liberdades básicas de cada um. Porém, Rawls faz a ressalva que nenhuma dessas liberdades é absoluta, devendo ser acomodadas dentro de um único sistema. As liberdades asseguradas por este princípio podem ser relacionadas como sendo:

(...) a liberdade de pensamento, a liberdade de consciência, a liberdade política (direito de votar e de ocupar cargo público), a liberdade de associação (reunião), as liberdades que mantêm a integridade da pessoa (incluem proteção contra a opressão psicológica e a agressão física), e as liberdades que asseguram direitos protegidos pelo Estado de Direito ou pelo que também se pode designar como o Império da Lei (direito à propriedade privada e à proteção contra a prisão e a detenção arbitrárias $)^{20}$.

Já o segundo princípio preceitua que: "as desigualdades econômicas e sociais devem ser ordenadas de tal modo que sejam ao mesmo tempo (a) consideradas como vantajosas para todos dentro dos limites do razoável, e (b) vinculadas a posições e cargos acessíveis a todos" ${ }^{21}$. Este princípio diz respeito à distribuição de riquezas e às organizações estatais que fazem este controle.

É importante salientar que o princípio não pugna por uma alocação de bens fundada em um padrão valorativo ou comparativo capaz de conferir regularidade à distribuição (igualdade simples ou simetria), porque isso implicaria a necessidade de operarem-se redistribuições ininterruptas dos bens entre os indivíduos, distribuições de bens que seriam injustas por não levarem em conta os resultados das escolhas de rumos e projeto de vida de cada indivíduo, ou seja, por não levarem em conta o que se pode denominar como a herança ou legado de cada geração ${ }^{22}$.

\footnotetext{
${ }^{19}$ MÖLLER. A justiça como eqüidade em John Rawls. p. 67.

20 MÖLLER. A justiça como eqüidade em John Rawls. p. 68.

${ }^{21}$ RAWLS, John. Uma teoria da justiça. São Paulo: Martins Fontes, 2000. p. 64

22 MÖLLER. A justiça como eqüidade em John Rawls. p. 73-74.
} 
RIGO, Mônica Giusti. Meio ambiente igualitário: análise da relação entre a justiça equitativa de Rawls e o princípio da "não-regressão" de Michel Prieur. Revista Eletrônica Direito e Política, Programa de Pós-Graduação Stricto Sensu em Ciência Jurídica da UNIVALI, Itajaí, v.10, n.1, edição especial de 2015. Disponível em: www.univali.br/direitoepolitica - ISSN 1980-7791.

O primeiro apontamento que deve ser feito é quanto à aplicabilidade de tais princípios, que deverá ocorrer de modo seqüencial, o primeiro princípio e após o segundo. Deste modo, nenhuma vantagem contida no segundo princípio poderá servir como indenização à violação de alguma liberdade contida no primeiro princípio. Para Rawls, portanto, a injustiça "se constitui simplesmente de desigualdades que não beneficiam a todos ${ }^{\prime 23}$.

Para o igualitarismo, e desde o pioneiro trabalho de John Rawls sobre a teoria da justiça, os talentos devem ser considerados um mero produto da "loteria natural": alguns foram favorecidos e outros prejudicados nessa atribuição inicial de recursos internos, mas o sistema institucional não deve sobrecarregar os indivíduos com o peso dessa situação ${ }^{24}$.

Segundo esta regra, não existiriam níveis de injustiça a serem aceitos ou não, o único requisito básico para que se fosse feita justiça seria a melhora na vida de cada um, independente do nível de alcance deste avanço, pois seria medido de acordo com o ponto inicial de cada indivíduo.

Ambos princípios são aplicados as instituições básicas da sociedade. Especificamente em relação ao segundo princípio Rawls adota o Princípio da Igualdade Democrática. Consegue-se chegar a este raciocínio por meio da união do princípio da igualdade equitativa de oportunidades e o princípio da diferença, abordados a seguir.

\section{O PRINCÍPIO DA IGUALDADE EQUITATIVA DE OPORTUNIDADES}

Este princípio diz respeito aos critérios de acesso as oportunidades de cada um frente aos bens sociais. "Ele tem por fim neutralizar ou mitigar a influência dos fatores eticamente arbitrários para evitar que as expectativas de cidadãos que

\footnotetext{
${ }^{23}$ RAWLS, John. Uma teoria da justiça. São Paulo: Martins Fontes, 2000. p. 20.

${ }^{24}$ GARGARELA. As teorias da justiça depois de Rawls. Um breve manual de filosofia política. p. 29-30.
} 
RIGO, Mônica Giusti. Meio ambiente igualitário: análise da relação entre a justiça equitativa de Rawls e o princípio da "não-regressão" de Michel Prieur. Revista Eletrônica Direito e Política, Programa de Pós-Graduação Stricto Sensu em Ciência Jurídica da UNIVALI, Itajaí, v.10, n.1, edição especial de 2015. Disponível em: www.univali.br/direitoepolitica - ISSN 1980-7791.

possuam as mesmas habilidades sejam afetadas pela classe social a que pertencem" ${ }^{\prime 25}$.

Rawls traz o conceito das habilidades naturais como sendo uma loteria natural, na qual alguns possuem mais habilidades, vantagens e talentos que outros. Utilizando-se do princípio da igualdade equitativa de oportunidades ele estabelece regras para que os indivíduos que possuam as mesmas habilidades, ainda que de classe social baixa ou condição financeira inferior possam atingir os mesmos objetivos daqueles de classe social mais alta e condição financeira melhor.

O princípio da igualdade equitativa de oportunidades, ancorado em uma interpretação liberal igualitária que subjaz toda a teoria e pressupõe uma igualdade de tratamento (primeiro princípio de justiça) e uma economia de mercado livre, tem como objetivo assegurar a todos os indivíduos os mesmo direitos legais de acesso a todas as posições sociais privilegiadas $^{26}$.

Este entendimento não deve ser confundido com a noção de "carreiras abertas a talentos" ${ }^{27}$, não estando relacionado às sociedades meritocráticas, mas sim no sentido que todos agem e trabalham no intuito de um benefício geral da sociedade, em nível de bens e de direitos.

Segundo a teoria da justiça de Rawls "uma sociedade justa deve, na medida do possível, tender a igualar as pessoas em suas circunstâncias, de tal modo que o que ocorra em suas vidas fique sob sua própria responsabilidade" 28 . Deste modo, a estrutura básica da sociedade é regida por um sistema de regras procedimentais no intuito de todos atingirem expectativas possíveis dentro desta distribuição.

Um exemplo dessas circunstâncias é o fato de uma pessoa nascer em uma família com abundância em recursos financeiros, ou possuir talentos e

${ }^{25}$ MÖLLER. A justiça como eqüidade em John Rawls. p. 74-75.

${ }^{26}$ MÖLLER. A justiça como eqüidade em John Rawls. p. 74.

${ }^{27}$ RAWLS, John. Uma teoria da justiça. São Paulo: Martins Fontes, 2000. p. 70.

${ }^{28}$ GARGARELA. As teorias da justiça depois de Rawls. Um breve manual de filosofia política. p. 27. 
RIGO, Mônica Giusti. Meio ambiente igualitário: análise da relação entre a justiça equitativa de Rawls e o princípio da "não-regressão" de Michel Prieur. Revista Eletrônica Direito e Política, Programa de Pós-Graduação Stricto Sensu em Ciência Jurídica da UNIVALI, Itajaí, v.10, n.1, edição especial de 2015. Disponível em: www.univali.br/direitoepolitica - ISSN 1980-7791.

habilidades além dos normais. Uma pessoa que não se encontrasse em nenhuma das posições acima não poderia ter desvantagens na alocação em uma vaga de emprego ou estudo, devendo ser privilegiado na distribuição de recursos.

Somente poderá ocorrer essa distribuição favorável dentro do sistema devido a cooperação social dos indivíduos. "O consenso sobreposto procura garantir e dar sustentação à sociedade democrática almejada pela teoria da justiça como equidade" ${ }^{\prime 29}$.

Porém, se uma pessoa, apesar de possuir essa "vantagem natural", ou, ainda que não possuir tal vantagem estiver igualada aos demais, e decidir por possuir menos recursos financeiros devido ao seu estilo de vida, o sistema de distribuição de recursos seria considerado justo. Isso se dá devido ao fato de que os bens sociais foram distribuídos equitativamente, pois, foi à própria pessoa, sob sua própria responsabilidade, que decidiu por uma maneira diferente de vida.

A alocação dos itens produzidos ocorre de acordo com o sistema público de regras, e esse sistema determina o que é produzido, quanto é produzido, e por que meios. Também determina reivindicações legítimas que, quando respeitadas, criam a distribuição resultante. Assim, nesse tipo de justiça procedimental, a correção da distribuição está fundada na justiça do esquema de cooperação do qual ela surge e na satisfação das reivindicações de indivíduos engajados nele ${ }^{30}$.

Dessa resultante da teoria de Rawls, consegue-se perceber o fundamente liberalista, pois cada um é responsável pelas suas escolhas, e para onde estas os levaram. "Os indivíduos devem ser considerados responsáveis por suas ações, e não meras vítimas de seu destino, às quais o Estado sempre deve apoiar"131.

Rawls entende que o modo como a natureza distribui as vantagens não é justo ou injusto, mas que o sistema de distribuição de recurso sim, pode ser julgado como justo ou injusto. "O problema não é apenas redistribuir recursos que foram

\footnotetext{
${ }^{29}$ ZAMBAM. A teoria da justiça em John Rawls: uma leitura. p. 83.

${ }^{30}$ RAWLS, John. Uma teoria da justiça. São Paulo: Martins Fontes, 2000. p. 94.

${ }^{31}$ GARGARELA. As teorias da justiça depois de Rawls. Um breve manual de filosofia política. $p$. 27.
} 
RIGO, Mônica Giusti. Meio ambiente igualitário: análise da relação entre a justiça equitativa de Rawls e o princípio da "não-regressão" de Michel Prieur. Revista Eletrônica Direito e Política, Programa de Pós-Graduação Stricto Sensu em Ciência Jurídica da UNIVALI, Itajaí, v.10, n.1, edição especial de 2015. Disponível em: www.univali.br/direitoepolitica - ISSN 1980-7791.

desigualmente distribuídos, mas, primeiro, mudar as instituições econômicas que governam a distribuição de tais recursos, ou seja, mudar os critérios de distribuição"32. Deste modo, de acordo com o que já foi distribuído pela natureza, as instituições básicas devem fazer a distribuição dos recursos existentes.

Com isso, cada um irá ter a vida que desejou, sendo responsabilizado individualmente pelas ações que realiza. "O aproveitamento das oportunidades dependerá dos desejos de vontade, e de outras capacidades específicas dos indivíduos" ${ }^{33}$. Este sistema será justo pois, as condições iniciais de cada indivíduos serão iguais, ainda que não privilegiados pela loteria natural.

\begin{abstract}
A efetivação da igualdade equitativa requer que o regime social sofra condicionamentos complementares que, para resguardar condições sociais favoráveis, incluem adaptações - ou limitações - no sistema de mercado livre. Os instrumentos institucionais devem, entre outras medidas, passar a regular as tendências globais dos eventos econômicos, impedir (evitar) a concentração excessiva de propriedades e riquezas durante o processo social, e manter iguais oportunidades de educação a todos ${ }^{34}$.
\end{abstract}

\title{
3. O PRINCÍPIO DA DIFERENÇA
}

No princípio da diferença todos os homens da sociedade agem em concordância e cooperação, para que todos possam usufruir dos bens sociais. "O princípio da diferença, tal como está exposto, implica na superação de uma idéia de justiça distributiva, habitual nas sociedades modernas, segundo a qual o que cada um obtém é justo se os benefícios ou posições em questão também forem acessíveis aos demais" ${ }^{35}$.

Outrossim, diante deste princípio o benefício maior dos mais privilegiados somente seria possível se, diante disso, os menos favorecidos fossem

\footnotetext{
32 FARIAS. Ética, justiça e direito. p. 40.

${ }^{33}$ MÖLLER. A justiça como eqüidade em John Rawls. p. 75.

${ }^{34}$ MÖLLER. A justiça como eqüidade em John Rawls. p. 76.

${ }^{35}$ GARGARELA. As teorias da justiça depois de Rawls. Um breve manual de filosofia política. $p$. 25.
} 
RIGO, Mônica Giusti. Meio ambiente igualitário: análise da relação entre a justiça equitativa de Rawls e o princípio da "não-regressão" de Michel Prieur. Revista Eletrônica Direito e Política, Programa de Pós-Graduação Stricto Sensu em Ciência Jurídica da UNIVALI, Itajaí, v.10, n.1, edição especial de 2015. Disponível em: www.univali.br/direitoepolitica - ISSN 1980-7791.

beneficiados também. Isto é, somente poderia se operar desigualmente a distribuição dos recursos, se isso fosse beneficiar os menos favorecidos da sociedade em questão, mas nunca subtrair os seus recursos.

(...) o princípio da diferença zela pelo bem-estar do grupo dos desfavorecidos, garantindo-lhe as melhores condições que, sem porem em risco a liberdade, seja possível obter a prioridade lexical do princípio da liberdade garante aos indivíduos que se encontram nas posições sociais mais desfavorecidas o não poderem ser privados de importantes liberdades" ${ }^{\prime 36}$.

Este princípio juntamente com o princípio da equidade de oportunidades faz com que se possa alcançar a igualdade democrática buscada na teoria de Rawls. "Ela afirma que uma teoria da justiça não merece ser reconhecida como tal se permite que as pessoas sejam beneficiadas ou prejudicadas por circunstâncias alheias a sua vontade" ${ }^{37}$. Assim, busca-se mais que uma igualdade formal de aquisição de cargos, mas tem por objetivo combater as desigualdades advindas da "loteria natural".

Por este princípio se concebe a aceitação que se não houver uma maneira com que se dividam os bens sociais e ambas as partes tenham a sua situação melhorada, esta distribuição deve ser feita de maneira igualitária. "O critério da equidade não exclui desigualdades, mas prevê um direcionamento: deve beneficiar a todos. Rawls ao introduzir o princípio da diferença, procura maximizar a expectativa dos menos favorecidos ${ }^{38 \prime \prime}$.

Rawls não pretende que todos se estabeleçam em uma mesma situação social ou de recursos, mas que a distribuição dos bens seja justa, independente do estado inicial de cada um. Negar a existência das desigualdades torna impossível uma teoria na qual se tenha por objeto uma organização da sociedade justa. "A justiça de um esquema social depende essencialmente de como se atribuem

\footnotetext{
${ }^{36}$ KUKATHAS. Rawls: uma teoria da justiça e seus críticos. p. 61.

37 GARGARELA. As teorias da justiça depois de Rawls. Um breve manual de filosofia política. $p$. 26.
}

${ }^{38}$ ZAMBAM. A teoria da justiça em John Rawls: uma leitura. p. 73. 
RIGO, Mônica Giusti. Meio ambiente igualitário: análise da relação entre a justiça equitativa de Rawls e o princípio da "não-regressão" de Michel Prieur. Revista Eletrônica Direito e Política, Programa de Pós-Graduação Stricto Sensu em Ciência Jurídica da UNIVALI, Itajaí, v.10, n.1, edição especial de 2015. Disponível em: www.univali.br/direitoepolitica - ISSN 1980-7791.

direitos e deveres fundamentais e das oportunidades econômicas e condições sociais que existem nos vários setores da sociedade" ${ }^{\prime 39}$.

Deste modo, os princípios da justiça estabelecidos por Rawls tem como foco de aplicação a estrutura da sociedade básica, todas as pessoas deverão ser favorecidas com a acessibilidade de cargos. Todos os membros da sociedade desde os mais ricos até os menos favorecidos financeiramente seriam beneficiados por este sistema de bens sociais primários.

Ao estar inserido na teoria de justiça de Rawls, o princípio da diferença entende que "não se trata de redistribuir de maneira permanente e generalizada os "bens primários", mas de dotar equitativamente cada indivíduo desde o começo" ${ }^{\prime 40}$.

O princípio da diferença, constante da segunda parte do segundo princípio da justiça, ao regular a distribuição geral dos bens primários, elimina a indefinição ostentada pelo conhecido princípio da eficiência, segundo o qual a eficácia de uma organização social decorre da simetria da repartição (ganhos análogos), na medida em que acolhe a predileção por uma posição particular a partir da qual as desigualdades da estrutura básica da sociedade devem ser julgadas ${ }^{41}$.

Diante disso, a adesão deste princípio resulta na maximização dos benefícios dos menos favorecidos. Rawls entende que tendo em vista a aplicabilidade de sua teoria, e em sociedades reais existem pessoas menos favorecidas, ou em classes mais baixas.

De mesmo modo, algumas dessas pessoas de classes sociais mais baixas estão nessa situação por vontade própria, já outras em decorrência de eventos alheios a sua vontade. No segundo caso reside a aplicação do princípio da diferença. "A condição de beneficiar os membros menos privilegiados está contemplada como condição indispensável para a construção da justiça"42.

\footnotetext{
${ }^{39}$ RAWLS, John. Uma teoria da justiça. São Paulo: Martins Fontes, 2000. p. 8.

40 FARIAS. Ética, justiça e direito. p. 41.

${ }^{41}$ MÖLLER. A justiça como eqüidade em John Rawls. p. 76.

42 ZAMBAM. A teoria da justiça em John Rawls: uma leitura. p. 99.
} 
RIGO, Mônica Giusti. Meio ambiente igualitário: análise da relação entre a justiça equitativa de Rawls e o princípio da "não-regressão" de Michel Prieur. Revista Eletrônica Direito e Política, Programa de Pós-Graduação Stricto Sensu em Ciência Jurídica da UNIVALI, Itajaí, v.10, n.1, edição especial de 2015. Disponível em: www.univali.br/direitoepolitica - ISSN 1980-7791.

Os princípios da justiça devem ser considerados centrais na teoria da justiça. A estrutura básica da sociedade assenta-se nesses princípios, que dão legitimidade à existência da sociedade democrática; são critérios seguros para a existência e durabilidade das instituições, responsáveis para que todos, de forma equitativa, tenham acesso aos bens primários, à igualdade de oportunidades e ao exercício das liberdades básicas, priorizando o benefício aos membros menos favorecidos ${ }^{43}$.

Rawls entende que disparidades sociais sempre irão existir, e que o sistema irá auxiliar os indivíduos até determinado ponto, onde suas necessidades básicas serão atendidas, após este estágio, cada um será responsável pelas próprias ações, e as conseqüências serão recaídas sobre ele.

\section{RELAÇÃo ENTRE OS PRINCÍPIOS DE RAWLS E O PRINCÍPIO DA NÃO- REGRESSÃO}

O direito ao meio ambiente está intimamente ligado ao conceito do direito à vida, que esse direito está entendido como "um direito à sobrevivência face às ameaças que pesam sobre o planeta em consequência das múltiplas degradações dos ecossistemas" ${ }^{\prime 4}$.

Na realidade, a não regressão dos direitos humanos é muito mais que implícita, ela é ética, prática e quase jurídica. De acordo com a declaração universal dos direitos humanos, a finalidade destes é a de "favorecer ao progresso social e estabelecer melhores condições de vida". Resulta, portanto, numa obrigação positiva para os Estados, particularmente em matéria ambiental. Deste modo, a não regressão a despeito de sua aparente obrigação negativa conduz a uma obrigação positiva aplicada a uma norma fundamental. Distintos textos internacionais dos direitos humanos evidenciam a característica progressiva dos direitos econômicos, sociais e culturais, os quais estão normalmente ligados ao direito ambiental. Deduz-se facilmente desta

\footnotetext{
43 ZAMBAM. A teoria da justiça em John Rawls: uma leitura. p. 15.

44 PRIEUR, Michel. O princípio da "não regressão" no coração do direito do homem e do meio ambiente. Revista NEJ - Eletrônica, Itajaí, Vol. 17 - n. 1, p. 06-17, jan/abr 2012. ISSN: 2175-0491. p. 17.
} 
RIGO, Mônica Giusti. Meio ambiente igualitário: análise da relação entre a justiça equitativa de Rawls e o princípio da "não-regressão" de Michel Prieur. Revista Eletrônica Direito e Política, Programa de Pós-Graduação Stricto Sensu em Ciência Jurídica da UNIVALI, Itajaí, v.10, n.1, edição especial de 2015. Disponível em: www.univali.br/direitoepolitica - ISSN 1980-7791.

progressividade uma obrigação de não regressão ou não retrocesso ${ }^{45}$.

Rawls em sua teoria de justiça não buscou tratar de forma direta a questão ambiental. Ainda assim, é possível verificar "conceitos e raciocínios perfeitamente aplicáveis à temática da necessidade de proteção ao meio ambiente e da manutenção da qualidade ambiental capaz de assegurar a vida humana com dignidade ${ }^{\prime 46}$.

Os recursos dentro da filosofia de Rawls são aqueles bens, vantagens, deveres e/ou direitos fundamentais a serem distribuídos dentre a população. O meioambiente saudável é um direito fundamental de todos os cidadão, tanto dos presentes quanto dos futuros. Deste modo, ao realizar as políticas ambientais deve pensar em como esse meio ambiente deve perdurar dentre as gerações, e procurar concervá-lo.

Assim, o meio ambiente como recurso dentro da teoria de Rawls deve ser entendido não como um bem a ser distribuído somente entre aquela parcela da população presente. Mas deve ser preservado, de modo que as futuras gerações possam usufruir dele também.

O princípio da solidariedade ou equidade entre gerações foi internalizado pelo ordenamento brasileiro no caput do artigo 255 da Constituição Federal. Deste modo, a população atual é responsável por assegurar um meio ambiente saudável as gerações futuras.

Art. 225. Todos têm direito ao meio ambiente ecologicamente equilibrado, bem de uso comum do povo e essencial à sadia qualidade de vida, impondo-se ao Poder

\footnotetext{
45 PRIEUR. O princípio da "não regressão" no coração do direito do homem e do meio ambiente. p. 8.

46 LUMERTZ, Eduardo Só dos Santos. VIEIRA, Fabricio dos Santos. A justiça e o direito segundo John Rawls e a questão ambiental uma abordagem possível. Revista do Ministério Público RS. No 72. Porto Alegre. Acesso em Acesso em 29 de setembro de 2014. Disponível em: http://www.amprs.org.br/arquivos/ revista_artigo/arquivo_1363114189.pdf. p. 133
} 
RIGO, Mônica Giusti. Meio ambiente igualitário: análise da relação entre a justiça equitativa de Rawls e o princípio da "não-regressão" de Michel Prieur. Revista Eletrônica Direito e Política, Programa de Pós-Graduação Stricto Sensu em Ciência Jurídica da UNIVALI, Itajaí, v.10, n.1, edição especial de 2015. Disponível em: www.univali.br/direitoepolitica - ISSN 1980-7791.

Público e à coletividade o dever de defendê-lo e preservá-lo para as presentes e futuras gerações ${ }^{47}$.

Rawls em sua teoria refere a respeito do capital real. Ele se refere que cada geração deve conservar as instituições justas conquistadas, assim como os ganhos em cultura e civilização. Por mais que o filósofo não tenha tratado especificamente das questões relacionadas ao meio ambiente, é possível fazer uma relação entre este e a teoria.

Isso se dá devido ao fato de que a preservação do meio ambiente é parte integrante da dignidade da pessoa humana, devendo ser preservado pelas gerações presentes, em respeito às futuras. Logo "é possível estabelecer que o ideal de solidariedade de Rawls não se esgota na maximização da expectativa apenas dos menos favorecidos contemporâneos" ${ }^{48}$.

Logo, os princípios de justiça e os bens primários definidos por John Rawls podem ser considerados verdadeira salvaguarda da dignidade dos povos (e, por via de conseqüência, conteúdo mínimo existencial) - em relação aos quais não pode haver retrocesso ou supressão do mínimo essencial social já estabelecido pelos representantes do acordo hipotético - sob pena de se gerar desnecessária instabilidade institucional e social (que poderá levar, inclusive, como sugerido pelo próprio Rawls, à reformulação do Estado ou, até mesmo, à desobediência civil $)^{49}$.

Assim, a poupança a qual Rawls de refere dos recursos disponíveis, deve agir também em relação ao meio ambiente. Os recursos disponíveis a serem distribuídos pelo princípio da igualdade equitativa de oportunidades dizem respeito também ao meio ambiente saudável. Logo, o papel de distribuição literal deve ficar restrita a uma pequena parcela, preservando-se a maior parte deste bem maior da humanidade.

\footnotetext{
47 BRASIL. Constituição (1988).Constituição da República Federativa do Brasil. Disponível em: http://www.planalto.gov.br/ccivil_03/constituicao/constituicao.htm. Acesso em: 23 de setembro de 2014.

${ }^{48}$ LUMERTZ e VIEIRA. A justiça e o direito segundo John Rawls e a questão ambiental uma abordagem possível. p. 134.

${ }^{49}$ LUMERTZ e VIEIRA. A justiça e o direito segundo John Rawls e a questão ambiental uma abordagem possível. p. 136.
} 
RIGO, Mônica Giusti. Meio ambiente igualitário: análise da relação entre a justiça equitativa de Rawls e o princípio da "não-regressão" de Michel Prieur. Revista Eletrônica Direito e Política, Programa de Pós-Graduação Stricto Sensu em Ciência Jurídica da UNIVALI, Itajaí, v.10, n.1, edição especial de 2015. Disponível em: www.univali.br/direitoepolitica - ISSN 1980-7791.

\section{CONSIDERAÇÕES FINAIS}

A teoria da justiça equitativa de Rawls tem como base o livro Uma Teoria da Justiça, e nela estão descritos os principais objetivos da teoria da justiça igualitária do autor. Neste escrito apresenta-se a base da democracia constitucional entendida pelo autor.

Para os conceitos de dois princípios da justiça escolhidos por representantes de grupos variados da sociedade. Sob um "véu da ignorância", todos estes representantes iriam escolher princípios a serem regentes das instituições básicas da sociedade.

Ganha destaque nesta obra a maneira como o autor enfrentou a aplicabilidade da teoria, que para além do conceito "comum" das teorias da justiça, parte para um raciocínio prático na elaboração desta.

A teoria da justiça como equidade de Rawls, traz para além de uma distribuição simétrica de valores, das teorias habituais, um conceito de responsabilidade de cada indivíduo. Todos são postos em questão, tendo suas habilidades naturais e dons postos em valor de igualdade com aqueles que possuem maiores recursos financeiros.

Após realizada esta avaliação, o sistema iria redistribuir os bens sociais, entendidos como os básicos na sobrevivência de cada um. Após, cada um com igualdade de oportunidade de alocação em empregos e vagas, deveria, segundo a própria consciência, e sob sua responsabilidade, atingir os objetivos particulares de vida.

Sendo assim, a teoria de justiça de Rawls, parte de uma responsabilidade das entidades sociais em um primeiro momento no bem estar do indivíduo, e, posteriormente, após uma equidade de recursos e oportunidades, passa ao próprio indivíduo a responsabilização dos rumos de sua vida.

Neste sentido, vem à responsabilidade da sociedade e de cada um de seus membros com a proteção ao meio ambiente. Pois, para além de seguir seus 
RIGO, Mônica Giusti. Meio ambiente igualitário: análise da relação entre a justiça equitativa de Rawls e o princípio da "não-regressão" de Michel Prieur. Revista Eletrônica Direito e Política, Programa de Pós-Graduação Stricto Sensu em Ciência Jurídica da UNIVALI, Itajaí, v.10, n.1, edição especial de 2015. Disponível em: www.univali.br/direitoepolitica - ISSN 1980-7791.

objetivos individuais, o Estado deve pensar nas gerações futuras, e como as ações atuais irão influenciar na continuidade da humanidade.

O meio ambiente, diante desta análise, passa a ser um recurso que deve ser distribuído dentre todas as gerações humanas. Logo, o meio ambiente deve ser preservado, para que todas as gerações possam usufrui-lo.

\section{REFERÊNCIAS DAS FONTES CITADAS}

BRASIL. Constituição (1988). Constituição da República Federativa do Brasil. Disponível em: http://www.planalto.gov.br/ccivil_03/constituicao/constituicao.htm. Acesso em: 23 de setembro de 2014.

FARIAS, José Fernando de Castro. Ética, justiça e direito. Rio de Janeiro: Lumen Juris, 2004.

GARGARELA, Roberto. As teorias da justiça depois de Rawls. Um breve manual de filosofia política. São Paulo: Martins Fontes, 2008.

KUKATHAS, Chandran; PETTIT, Philip. Rawls: uma teoria da justiça e seus críticos. Lisboa: Gadiva, 1995.

LUMERTZ, Eduardo Só dos Santos. VIEIRA, Fabricio dos Santos. A justiça e o direito segundo John Rawls e a questão ambiental uma abordagem possível. Revista do Ministério Público RS. No 72. Porto Alegre. Acesso em Acesso em 29 de setembro de 2014. Disponível em: http://www.amprs.org.br/arquivos/revista_artigo/arquivo_1363114189.pdf.

MÖLLER, Josué Emilio. A justiça como eqüidade em John Rawls. Porto Alegre: S. A. Frabris, 2006.

PRIEUR, Michel. O princípio da "não regressão" no coração do direito do homem e do meio ambiente. Revista NEJ - Eletrônica, Itajaí, Vol. 17 - n. 1, p. 06-17, jan/abr 2012. ISSN: 2175-0491.

RAWLS, John. Uma teoria da justiça. São Paulo: Martins Fontes, 2000.

ZAMBAM, Neuro José. A teoria da justiça em John Rawls: uma leitura. Passo Fundo: Ed. Universidade de Passo Fundo, 2004.

Submetido em: Setembro/2014

Aprovado em: Outubro/2014 